\title{
Thermal conductivity of plasma modified polyethylene terephthalate and polyamide-6 layers
}

\author{
G. Kalácska ${ }^{1}$, R. Keresztes ${ }^{1}$, L. Földi $^{1}$, Sz. Klébert ${ }^{2 *}$, Z. Károly ${ }^{2}$, L. Zsidai $^{1}$ \\ ${ }^{1}$ Institute for Mechanical Engineering Technology, Szent István University, Páter Károly u.1, H-2100 Gödöllő, Hungary \\ ${ }^{2}$ AKI, Research Centre for Natural Sciences, Magyar tudósok krt. 2., H-1117, Budapest, Hungary
}

Received 23 September 2015; accepted in revised form 2 December 2015

\begin{abstract}
Tribological performance of the materials greatly depends on the temperature of the contacting zones and surfaces and hence on the heat conducting behaviour of the materials. Heat conduction of polymers is, however, greatly affected even by a very narrow (few tens of $\mathrm{nm}$ ) modified layer formed on the surface after subjecting the polymer to plasma treatment. In this article the heat flow inhibiting properties of plasma modified surface layers were investigated on polyethylene terephthalate (PET) and polyamide-6 (PA6) engineering polymers. Nitrogen Plasma Immersion Ion Implantation gave rise to compositional and structural changes of the polymers in a depth of $110 \mathrm{~nm}$. It was found that even this thin layer exhibited significant heat flow inhibiting effect. The modified layer considerably decreased the thermal conductivity coefficient of the treated polymer and resulted in a reduced heat transmission for PET and PA6 by 33 and $28 \%$, respectively. This new information supports and is in accordance with the former tribological results about extra friction heat generation experienced under NPIII surface layer of PA6 and PET during dry sliding.
\end{abstract}

Keywords: thermal properties, surfaces, adhesion, ion implantation, tribology

\section{Introduction}

There is an increasing tendency to replace metal components by various kinds of engineering plastics [1]. The application of polymers for sliding parts is beneficial due to their corrosion resistance, damping characteristics and self-lubricating abilities [2]. Their use can reduce the maintenance costs, too. Several studies on the tribological behaviour of the most common engineering plastics [polyamides (PA) [3], polyoxymethylene (POM) [4] and polyethylene terephtalate with polytetrafluoroethylene (PET/ PTFE) [5] in contact with steel have been published and compared by, e.g., Tanaka [6], Evans and Senior [7], Guezmil et al. [8] and Kalácska [1].

Polymers as viscoelastic materials are greatly sensitive to the heat of friction. During sliding ca. 90$95 \%$ of the mechanical energy is transformed to heat [9]. The velocity of sliding affects wear and friction through the temperature of the contacting surfaces. At high sliding velocities the increased surface roughness increases the friction coefficient and consequently the interface temperature, too $[10,11]$. The thermal state of contact points is often decisive on the evaluation of frictional materials. Control of temperature at the polymer contact zone is of the highest importance to ensure beneficial wear and friction behaviour, because any increase in temperature may induce changes in the material bulk properties $[12,13]$ and polymer transfer processes. The thermal behaviour of the counter-surface could be also crucial for the temperature and tribological performance of the contact surfaces. Frictional metallic surfaces commonly possess good thermal conductivity and thus they can promote elimination of excessive heat. Metal surfaces, however, are commonly coated with metallic or ceramic layers or high hardness

\footnotetext{
*Corresponding author, e-mail: klebert.szilvia@ttk.mta.hu (c) BME-PT
} 
thin films [14-17], to increase their wear resistance. It was found that dry adhesion sliding can significantly increase the surface temperature because of the heat inhibiting effect of the surface layer. Not only metal parts are coated but surfaces of various polymers are also commonly modified $[18,19]$ to obtain an enhanced wear resistant outer surface layer having elevated hardness. Large number of papers have been published on plasma immersion ion implantation (PIII) modified polymers over the last decade and the results are summarized in a few review articles [20-23]. The research in this area focused mainly on the chemical, mechanical and morphological properties of PIII-modified polymer surfaces [24], but properties including wettability, electrical resistance and medical applicability were also investigated [25]. Surface treatment induce compositional and structural changes in the polymer in quite a limited depth (usually $20-100 \mathrm{~nm}$ ) only, but even this thin modified layer exhibits more favourable - mechanical properties. There is very limited information available, if any, about the thermal behaviour of this layer even though it can play a crucial role on the contact temperature of the plasma treated polymers and ultimately on the tribological properties, as well. This was confirmed by our former studies [26, 27], in which we investigated the tribological characters of plasma treated polymers (PET and PA6) by pinon-disc method. We proved that under water- and oil lubricated conditions the NPIII layer formed on PA6 can be advantageous in enhancing the lubricating effects [26]. Similar phenomenon was discovered in hip-joint application having synovial lubricating liquid on NPIII treated UHMW-PE surfaces [28, 29] and transferred to engineering practice (coated joints are produced). Under dry sliding the tribological results of NPIII layer formed on PA6 and PET were not so convincing [26, 27]. We showed for both polymer types that under dry sliding conditions at higher ' $p v$ ' values $\left(>0.1 \mathrm{MPa} \cdot \mathrm{ms}^{-1}\right)$ there was substantial difference in the sample temperature between the surface treated and untreated polymers, although the changes of the frictional coefficient did not imply such temperature difference. We attributed the finding to the heat inhibiting effect of the modified surface layer. In the present paper we report about a special experiment to confirm our previous hypothesis. Tests were performed on PET and PA6 engineering polymers, the tribological properties of which are of greater significance and were the objects in our former investigations, too.

\section{Experimental}

Heat flow inhibiting effect of thin layers was investigated by comparing the surface treated and untreated polyethylene terepthalate (PET) and polyamide 6 (PA6) using updated shielding test method already introduced elsewhere [30]. Commercial extruded PA6 and PET rods with diameter of $15 \mathrm{~mm}$ manufactured by Ensinger GmbH, supplied by Quattroplast Ltd (Hungary) were used. The disc-shaped sample with a diameter of $10 \mathrm{~mm}$ were machined with a thickness of $2 \mathrm{~mm}$. Before the NPIII treatment the samples were polished on wet $\mathrm{SiC}$ papers (grit numbers P1200 and P4000) and on felt sheet and were subsequently cleaned in ultrasonic bath of distilled water and of $96 \%$ ethanol. The samples were dried in pure nitrogen flow then treated by nitrogen plasma immersion ion implantation (N PIII) in a single run. The base pressure in the chamber was $4 \cdot 10^{-4} \mathrm{~Pa}$. A $27.13 \mathrm{MHz}$ RF plasma generator was applied (Dressler, Germany). High purity (4.5) $\mathrm{N}_{2}$ was used with a flow rate of $25 \mathrm{~cm}^{3} \cdot \mathrm{min}^{-1}$ (STP), radiofrequency power of $75 \mathrm{~W}$. The PIII treatment of the samples was performed by a high voltage pulser (ANSTO, Australia) with an accelerating voltage of $30 \mathrm{kV}$, ion fluence of $3 \cdot 10^{-17} \mathrm{~cm}^{-2}$ and fluence rate of $5 \cdot 10^{13} \mathrm{~cm}^{-2} \cdot \mathrm{s}^{-} 1$.

Surface composition of the modified layer was determined by XPS (X-ray photoelectron spectroscopy) analysis by a Kratos XSAM800 spectrometer using $\mathrm{MgK} \alpha_{1,2}$ radiation and fixed analyser-transmission mode (using 80 and $40 \mathrm{eV}$ pass energies for survey and detailed spectra, respectively). The thickness of plasma modified layer was estimated by the commonly used SRIM program [26].

Experimental set-up of heat flow tests is presented on Figure 1. Both the treated and untreated samples were heated by heat jet of $100^{\circ} \mathrm{C}$ initial temperatures through the bore of a POM-C heat insulating plate having a diameter of $9 \mathrm{~mm}$ and thickness of $10 \mathrm{~mm}$. The two sets of heating distance $\left(L_{2}=8 \mathrm{~mm}\right.$ and $L_{3}=$ $20 \mathrm{~mm}$ from the upper level of the insulating plate) resulted in different $T_{\mathrm{s}}$ temperatures (Figure 1b). The nozzle of the heat jet was fixed on the precision stand of a Mitutoyo bench, whereas the sample along with the POM C insulator plate were mounted on a $15 \mathrm{~mm}$ thick PA66-GF30 insulator that was laid on 

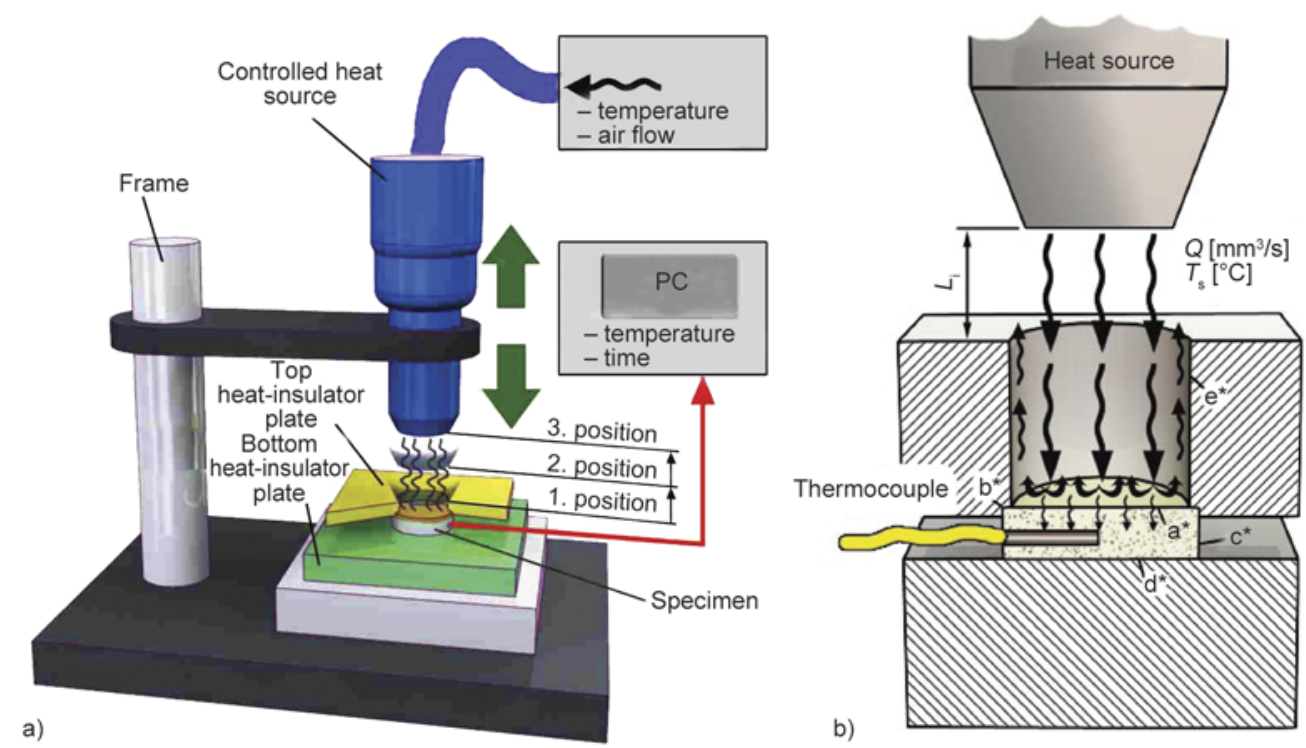

Figure 1. $(a-b)$ Experimental set-up for the measurement of heat inhibiting effect of the PIII layer

a granite base. The $2 \mathrm{~mm}$ thick sample discs were centred at the bottom of the upper heat insulator plate in a $0.3 \mathrm{~mm}$ depth seat. A K type thermocouple was inserted into the sample in a $0.8 \mathrm{~mm}$ bore at middle height to record the temperature as a function of time. The obtained values were a good approximation of the actual average temperature of the sample. The sample temperature values were recorded three times repeated at set heights of $L_{2}$ (2 position) and $L_{3}$ (3 position), respectively. The heat flow tests were carried out with PIII layers facing to the heat jet (curves hereinafter denoted as ' $c$ ') and with opposite side of the heat jet (curves hereinafter denoted as ' $a$ '). Reference measurements were also performed using untreated samples (curves hereinafter denoted as ' $b$ ').

\section{Results and discussion}

\subsection{Surface characterization}

According to the XPS analysis both the surface composition and the bond structures of the components are changed as a result of N PIII treatment for both polymers. Surface chemical compositions before and after treatments are given in Table 1. The compo-

Table 1. Surface composition of the un-treated and N PIII treated PET and PA6 samples determined by XPS analysis

\begin{tabular}{|l|c|c|c|c|}
\hline \multicolumn{1}{|c|}{ Sample } & $\begin{array}{c}\mathbf{O} \\
{[\mathbf{\%}]}\end{array}$ & $\begin{array}{c}\mathbf{N} \\
{[\mathbf{\%}[}\end{array}$ & $\begin{array}{c}\mathbf{C} \\
{[\mathbf{\%}]}\end{array}$ & Reference \\
\hline Un-treated PET & 28 & 0 & 72 & {$[20]$} \\
\hline N PIII treated & 18 & 15 & 67 & {$[20]$} \\
\hline Un-treated PA6 & 10 & 7 & 82 & {$[23]$} \\
\hline N PIII treated & 8 & 15 & 77 & {$[23]$} \\
\hline
\end{tabular}

sitional changes can be attributed to nitrogen incorporation into the surface layers from the plasma. It was found in earlier works that N PIII treatment resulted in the degradation of amide groups and the formation of imine, protonated amine as well as urethane-like structures [31]. A detailed discussion of XPS analysis of the modified layers including the XPS spectra has been reported elsewhere [23].

\subsection{Heating tests results}

Typical temperature plots are illustrated in Figure 2 (at $L_{3}=20 \mathrm{~mm}$, slow heating) and Figures 3 and 4 (at $L_{2}=8 \mathrm{~mm}$, intensive heating). During slow heating $\left(L_{3}\right)$ the temperature of the sample follows a theoretical saturation curve up to ca. 60-70 seconds, i.e. section I. In this section environmental effects can be neglected. Later on time in section II heat exchange commences at the contacting interface of the insulator mask and the seat where the sample is placed, which results in an additional quasi linear temperature increase from the 'saturated' level. Temperature of curve 'a' exceed that of the reference sample even in section I (around 20-25 s on Figure 2.) due to the heat inhibiting effect of the PIII treated layer since transmission of the accumulated heat in the sample is hindered at the bottom surface. The test reveals that the heat inhibiting effect of the PIII treated layer is significant especially for setting ' $c$ '. The role of the PIII treated layer in the heat transport can be studied with greater accuracy during rapid heating, i.e. under conditions that can be considered as quasi adiabatic. Heating tests therefore were continued for additional 60 seconds in unvar- 

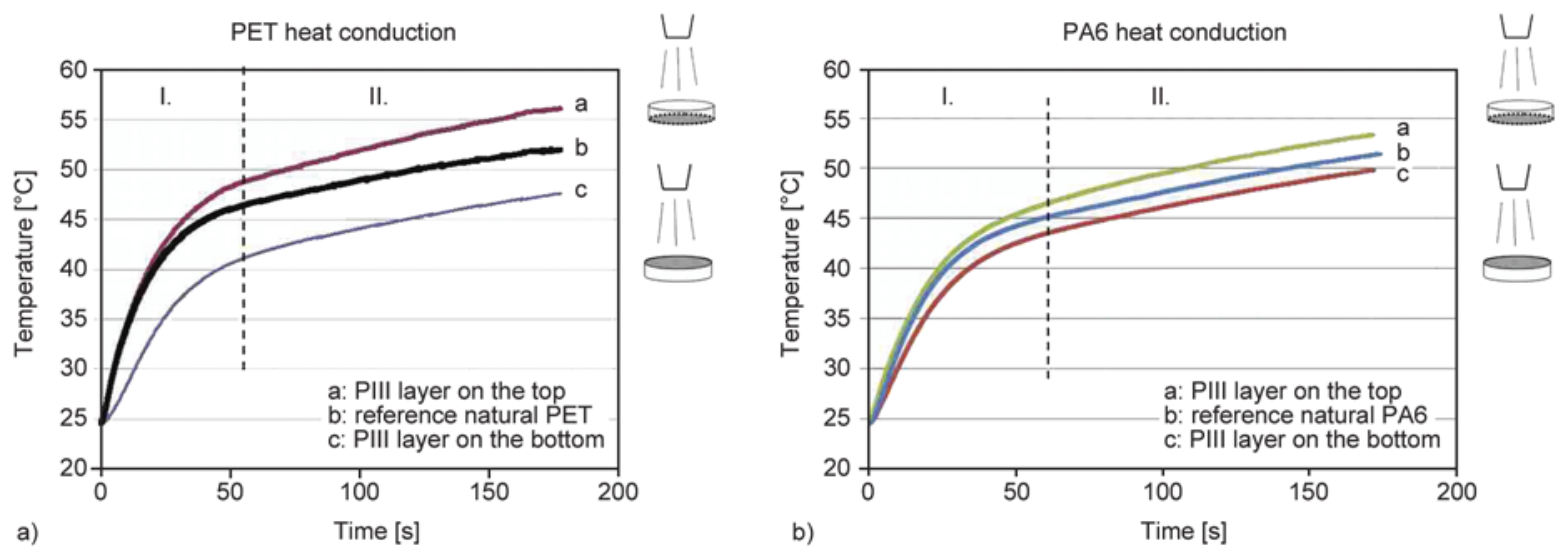

Figures 2. Temperature of sample PET (a) and PA6 (b) in the middle in slow heating conditions $\left(L_{3}\right)$

ied thermal and heat blowing conditions from distance $L_{2}$ (i.e. closer to the sample surface) (Figure 1a). The heat inhibiting effect of the PIII treated layer is even more obvious on Figure 3. that shows the intensively heated samples. When the modified layer is on top position the sample becomes warm (curve ' $c$ ') in less extent as compared to reference curve ' $b$ ' (pristine PET sample) that can be attributed to the inferior thermal conducting and reflecting properties of the modified thin layer.

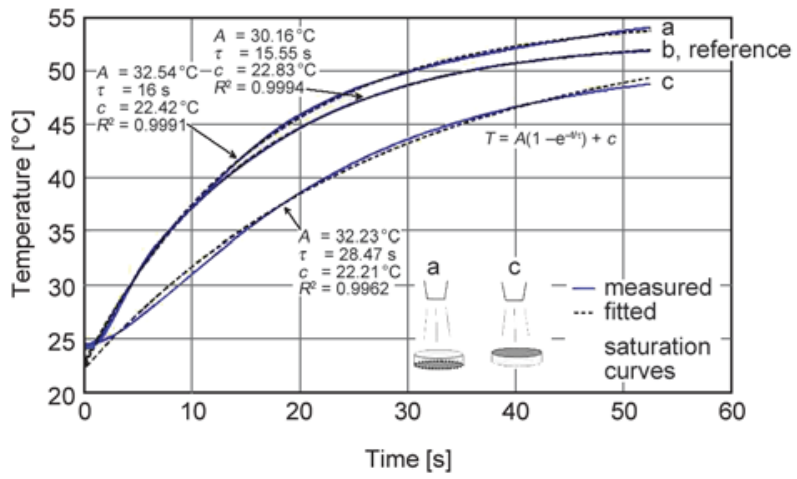

Figure 3. Temperature of sample PET in the middle under rapid heating conditions ( $\mathrm{a}$ - distance $L_{1}, \mathrm{~b}$ - distance $\left.L_{2}\right)$

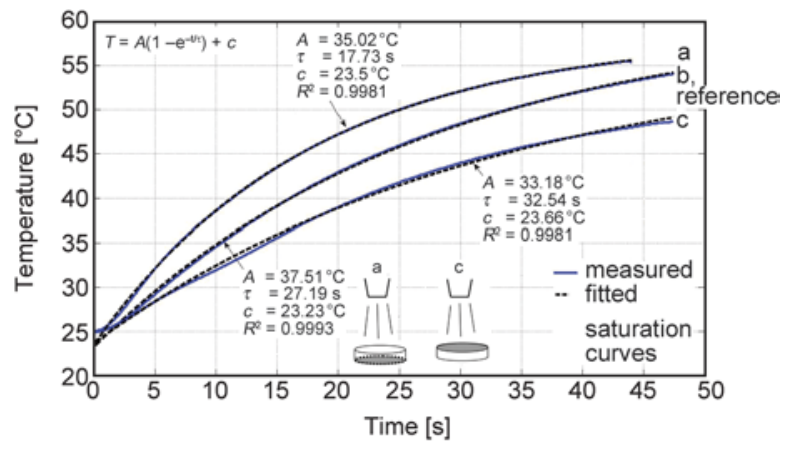

Figure 4. Temperature of sample PA6 in the middle under intensive heating conditions (from $L_{2}$ according to Figure 1b)
Comparing Figures 3 and 4 it can be concluded that intensive heating resulted in similar, although not identical, differences in the temperature history of PET and PA6. During less intensive heating with prolonged time (Figure 2a, 2b) the PIII modified thin layer on PET exhibited a higher heat inhibiting effect than that of PA6.

Heat flow induces three mechanisms in the sample: reflection, transmission and absorption. Assuming quasi adiabatic conditions transmission can be neglected, whereas the reflection being unknown is treated together with the absorption of heat hereinafter. Thus, the correct heat flow inhibiting effect of the layer can be quantified with an 'apparent thermal conductivity coefficient' that also includes reflection. There is an extensive literature on the reflection of modified polymers for solar and reflective glass technique, optics, wrapping and safety films, etc. [32]. Its proper determination, however, is rather complex and complicated as it depends on lots of parameters including the radiation spectrum, the chemical and structural composition, the substrate material, the layer thickness, etc. [33]. We used the energy and heat equations of absorption phenomena to quantify the heat flow inhibiting effect of the PIII modified layer. However, we note that heat reflection also contributes to the heat flow inhibiting effect of the PIII modified layer to a certain extent, thus heat absorption equations define an apparent linear thermal conducting coefficient.

Heat flow inhibiting phenomenon can be observed in two aspects in Figure 3. If PIII layer is at the bottom, the heat transmitted through within the polymer matrix encounters an insulating effect at the bottom that leads to temperature increase within the sample as compared to the non-treated (reference) one. The heat flow inhibiting phenomenon occurs $10-12 \mathrm{sec}-$ 
onds after curve ' $a$ ' exceeds reference curve ' $b$ '. The three measurements follow the theoretical saturation function with fair correlation (Equation (1)). They differ only in their coefficient (Figure 3):

$y=A\left(1-\mathrm{e}^{\frac{-\mathrm{t}}{\tau}}\right)+c$

where where $\tau$ is a time constant. In addition to the knowledge of the absolute temperature curves it is also vital to know the exact rate of temperature rise, the intensity of that at a given time with regard to the PIII modified and non-modified layers, which can help to judge its influence on the tribology. Derivation of fit curves on Figure 3 (Figure 5) results in the rate of temperature rise in the function of time for (Equation (2)) particular settings (a, b, c) in the form of:

$y^{\prime}=\frac{A}{\tau \mathrm{e} \frac{\mathrm{t}}{\tau}}$

When the heat flow reaches the surface of the matrix the rate of temperature difference is almost identical (Figure 5 reference sample ' $b$ ' and curve ' $a$ ' PIII modified layer at bottom position). Due to the inhibiting effect of the PIII modified layer at bottom position curve ' $a$ ' has a higher initial value but after $40-45$ seconds the rate of difference becomes identical at the value of $0.25^{\circ} \mathrm{C} / \mathrm{s}$. Curve 'c' clearly shows the slower warming of the sample if inhibiting layer is at top position. Temperature difference starts at a value of $60 \%$ of the reference curve ' $b$ ' but attain a little bit higher value at the end of the measurement due to the prolonged process. The figure also suggests that the heat flow inhibiting effect is more obvious for short intensive heating than for slow heating that result in more homogenous thermal conditions.

The measurements allowed the more accurate thermal analysis of the model. The temperature rise functions (Figure 3) obtained under rapid heating

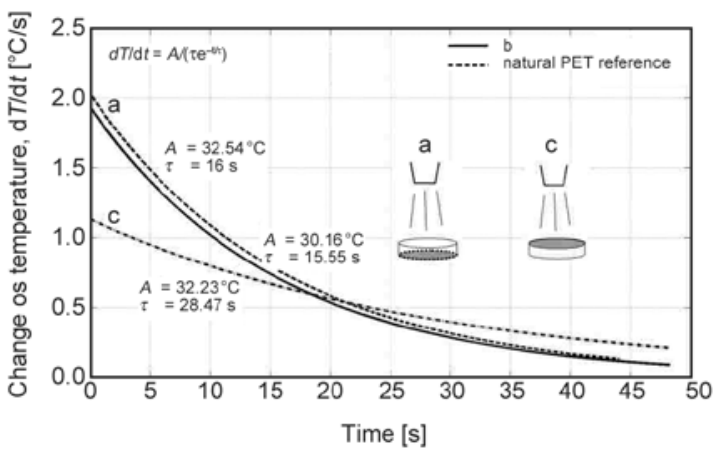

Figure 5. Rate of the temperature rise in sample PET are the result of the heat transmission occurring at surfaces $a^{*}, c^{*}$ and $d^{*}$ on Figure $1 \mathrm{~b}$, whereas the effect of the surfaces $b^{*}$ and $e^{*}$ can be neglected. The energy-balance differential equation of the system is written as [34]:

$\dot{E}_{\mathrm{i}}(t)-\dot{E}_{0}(t)=\frac{\mathrm{d} E_{\mathrm{t}}}{\mathrm{d} t}$ further

$c \cdot m \cdot \dot{T}(t)=Q_{\mathrm{a}^{*}}(t)-Q_{\mathrm{c}^{*}}(t)-Q_{\mathrm{d}^{*}}(t)$

where $E_{\mathrm{i}}$ stands for energy input, $E_{0}$ for energy output, $E_{\mathrm{t}}$ for stored energy and $Q_{\mathrm{x}}$ for heat (Equation (3)).

On surfaces $a^{*}$ and $c^{*}$ convection predominates, whereas on surface $d^{*}$ conduction takes place. Differential form of Equation (3), which expresses the temperature at the middle of the sample can be written as Equation (4):

$$
\begin{aligned}
c \cdot m \cdot \frac{\mathrm{d} T}{\mathrm{~d} t} & =\kappa_{\mathrm{a}} \cdot A_{\mathrm{a}}\left(T_{\mathrm{S}}-T\right)-\kappa_{\mathrm{c}} \cdot A_{\mathrm{c}}\left(T-T_{0}\right)- \\
& -\frac{\lambda_{\mathrm{d}}}{\delta_{\mathrm{d}}} \kappa_{\mathrm{a}} \cdot A_{\mathrm{d}}\left(T-T_{0}\right)
\end{aligned}
$$

where $\kappa_{\mathrm{x}}$-represents heat transmission of the given surface, $A_{\mathrm{x}}$ - represents the surface area, $c$ - specific heat, $m$ - mass.

With numerical integration of the equation both heat transmission of particular sample disc and the apparent linear thermal conductivity coefficient of PIII modified layer can be determined. Model calculations were carried out using code Matlab. Model identification was performed at first to non-modified PET samples. The last term at the right side of Equation (4) that represents heat transmission toward the insulating plate under the sample disc was calculated using the values of $\lambda_{\mathrm{d}}=0,24 \mathrm{~W} /\left(\mathrm{m}^{2} \mathrm{~K}\right), \delta_{\mathrm{d}}=$ $15 \mathrm{~mm}, A_{\mathrm{d}}=78,5 \mathrm{~mm}^{2} T_{0}=23^{\circ} \mathrm{C}$, all of which are identical to every known PA66-GF30 insulating materials. The middle term of the right side represents the free convection at the sample-air interface. The commonly used value of free convection is $20 \mathrm{~W} /\left(\mathrm{m}^{2} \cdot \mathrm{K}\right)$. The surface area is $A_{\mathrm{c}}=53.38 \mathrm{~mm}^{2}$. Regarding the non-treated reference sample with a virtual surface layer composed of its own substance in a thickness identical to PIII modified layer the ка heat transmission can be expressed as Equation (5):

$$
\kappa_{\mathrm{a}}=\frac{1}{\frac{1}{\alpha_{\mathrm{a}}}+\frac{\delta}{\lambda_{\mathrm{PET}}}}
$$


The virtual layer thickness of the non-treated PET $(\delta)$ is $103.6 \mathrm{~nm}$ (similar to PIII modified layer), whereas the linear thermal conducting coefficient $\left(\lambda_{\text {РЕTP }}\right)$ is $0.28 \mathrm{~W} /(\mathrm{m} \cdot \mathrm{K})$ and the measured temperature $\left(T_{\mathrm{s}}\right)$ is $61.2^{\circ} \mathrm{C}$.

By substituting Equation (5) to Equation (4) the forced convection coefficient $\left(\alpha_{\mathrm{a}}\right)$ as the single unknown is left that is characteristic of the surface of the sample in the experimental system. Having performed the model identification it can be concluded that the temperature rise curve of the reference PET sample (curve 'b' on Figure 3) and the calculated curve of the model show good correlation (Figure 6).

For PIII treated sample using the as-calculated convection coefficient $\left(\alpha_{\mathrm{a}}\right)$ and the given value of $\kappa_{\mathrm{a}}$ (150.0665 and $150,0582 \mathrm{~W} /\left(\mathrm{m}^{2} \cdot \mathrm{K}\right)$, respectively) only the apparent linear conducting coefficient of the surface layer $\left(\lambda_{\mathrm{PIII}}\right)$ is left as unknown. Performing the model calculation we obtained Figure 7 for the treated PET sample. Calculations were made in a similar manner for PA6 samples. The obtained results of the thermal model calculations are summarized in Table 2 for both polymers.

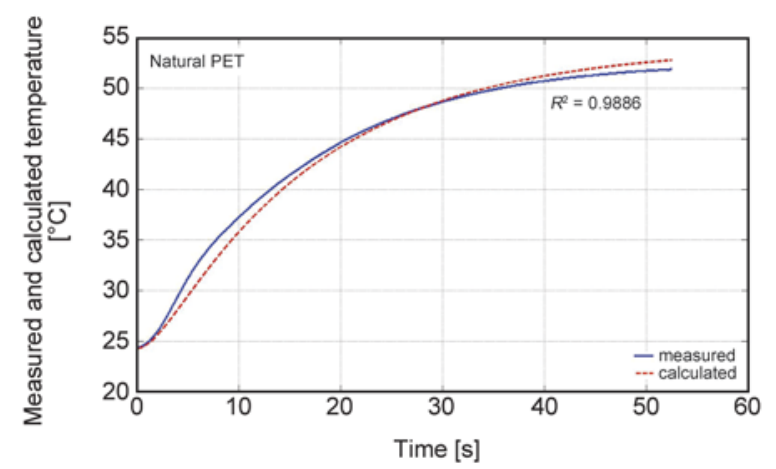

Figure 6. Measured and the calculated values of the temperature for un-treated PET sample, model identification

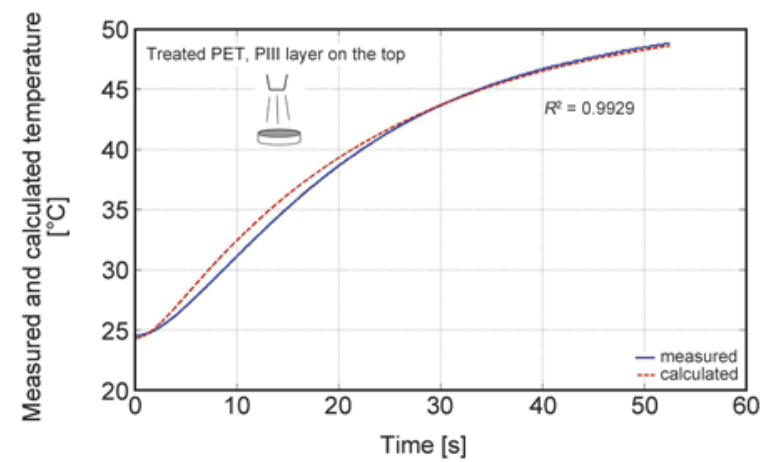

Figure 7. Measured and the calculated values of the temperature for treated PET sample
Table 2. Measured heat parameters in the model

\begin{tabular}{|l|c|c|}
\hline & $\begin{array}{c}\text { Heat } \\
\text { transmission, } \\
\boldsymbol{\kappa} \\
{\left[\mathbf{W} /\left(\mathbf{m}^{2} \cdot \mathbf{K}\right)\right]}\end{array}$ & $\begin{array}{c}\text { Apparent linear } \\
\text { thermal conducting } \\
\text { coefficient, } \boldsymbol{\lambda} \\
{[\mathbf{W} /(\mathbf{m} \cdot \mathbf{K})]}\end{array}$ \\
\hline Un-treated PET & 150.058 & 0.28 \\
\hline $\begin{array}{l}\text { PIII treated PET } \\
\text { Layer closer to heat jet }\end{array}$ & 99.408 & $3.0508 \cdot 10^{-5^{*}}$ \\
\hline Un-treated PA6 & 160.672 & 0.23 \\
\hline $\begin{array}{l}\text { PIII treated PA6 } \\
\text { Layer closer to heat jet }\end{array}$ & 115.0255 & $4.4902 \cdot 10^{-5^{*}}$ \\
\hline
\end{tabular}

${ }^{*}$ regarding to the treated PIII layer

It can be concluded from Table 2 that the PIII modified layers reduced heat transmission by ca. $30 \%$. We attributed this result to the several orders of magnitude lower (at least four orders in the model system) apparent linear thermal conducting coefficient of the modified layer than that of the pristine polymers. The heat flow inhibiting effect of the PIII treated surface layer occurred in both arrangements of the sample discs. On heating the sample discs, the temperature under the modified layer was lower than that in the untreated sample. In the opposite arrangement (i.e. the treated layer is at the bottom) the modified layer represented an obstacle for heat transmission toward the insulating plate.

\section{Conclusions}

In the present paper heat flow inhibiting properties of plasma surface modified thin layers were investigated on PET and PA6 engineering polymers. Nitrogen Plasma Immersion Ion Implantation induced considerable compositional and the microstructural changes in a depth of $110 \mathrm{~nm}$ of the polymers. We found that even this thin layer exhibited a significant heat flow inhibition. The modified layer resulted in a reduced heat transmission for PET and PA6 by 33 and $28 \%$, respectively. We attribute this result to the much smaller apparent linear thermal conducting coefficient of the treated polymer. The heat flow inhibiting effect of the PIII modified surface layer prevails regardless of the position of the treated side.

Sample temperature was lower as compared to reference one if heating occurred through the modified layer, whereas in opposite arrangement, the layer hindered the heat transmission toward the contacting plate holding the heat inside the polymer. The results can be of great significance to understand the tribological performance of plasma treated polymers. 


\section{Acknowledgements}

This work was supported by OTKA K 113039

\section{References}

[1] Kalácska G.: An engineering approach to dry friction behaviour of numerous engineering plastics with respect to the mechanical properties. Express Polymer Letters, 7, 199-210 (2013).

DOI: $10.3144 /$ expresspolymlett.2013.18

[2] Fusaro R. L.: Self-lubricating polymer composites and polymer transfer film lubrication for space applications. Tribology International, 23, 105-122 (1990).

DOI: 10.1016/0301-679X(90)90043-O

[3] Byett J. H., Allen C.: Dry sliding wear behaviour of polyamide 66 and polycarbonate composites. Tribology International, 25, 237-246 (1992). DOI: 10.1016/0301-679X(92)90061-Q

[4] Kar M. K., Bahadur S.: The wear equation for unfilled and filled polyoxymethylene. Wear, 30, 337-348 (1974). DOI: 10.1016/0043-1648(74)90148-3

[5] Gong D., Xue Q., Wang H.: Physical models of adhesive wear of polytetrafluoroethylene and its composites. Wear, 147, 9-24 (1991).

DOI: $10.1016 / 0043-1648(91) 90115-B$

[6] Tanaka K.: Transfer of semicrystalline polymers sliding against a smooth steel surface. Wear, 75, 183-199 (1982). DOI: 10.1016/0043-1648(82)90147-8

[7] Evans D. C., Senior G. S.: Self-lubricating materials for plain bearings. Tribology International, 15, 243-248 (1982).

DOI: $10.1016 / 0301-679 X(82) 90077-9$

[8] Guezmil M., Bensalah W., Mezlini S.: Effect of biolubrication on the tribological behavior of UHMWPE against M30NW stainless steel. Tribology International, 94, 550-559 (2016).

DOI: $10.1016 /$ j.triboint.2015.10.022

[9] Myshkin N. K., Petrokovets M. I., Kovalev A. V.: Tribology of polymers: Adhesion, friction, wear, and masstransfer. Tribology International, 38, 910-921 (2005). DOI: $10.1016 /$ j.triboint.2005.07.016

[10] Zhang S. W.: State-of-the-art of polymer tribology. Tribology International, 31, 49-60 (1998). DOI: $10.1016 / \mathrm{S} 0301-679 \mathrm{X}(98) 00007-3$

[11] Nosko O., Nagamine T., Nosko A. L., Romashko A. M., Mori H., Sato Y.: Measurement of temperature at sliding polymer surface by grindable thermocouples. Tribology International, 88, 100-106 (2015).

DOI: $10.1016 /$ j.triboint.2015.03.015

[12] Samyn P., De Baets P., Schoukens G., Quintelier J.: Wear transitions and stability of polyoxymethylene homopolymer in highly loaded applications compared to small-scale testing. Tribology International, 40, 819833 (2007).

DOI: $10.1016 /$ j.triboint.2006.08.003
[13] Samyn P., De Baets P., Schoukens G., Van Peteghem A. P.: Large-scale tests on friction and wear of engineering polymers for material selection in highly loaded sliding systems. Materials and Design, 27, 535-555 (2006).

DOI: $10.1016 /$ j.matdes.2004.12.021

[14] Zsidai L., Samyn P., Vercammen K., Van Acker K., Kozma M., Kalácska G., De Baets P.: Friction and thermal effects of engineering plastics sliding against steel and DLN-coated counterfaces. Tribology Letters, 17, 269-288 (2004). DOI: 10.1023/B:TRIL.0000032453.09366.d4

[15] Rafaja D., Wüstefeld C., Motylenko M., Schimpf C., Barsukova T., Schwarz M. R., Kroke E.: Interface phenomena in (super)hard nitride nanocomposites: From coatings to bulk materials. Chemical Society Reviews, 41, 5081-5101 (2012).

DOI: $10.1039 / C 2 C S 15351 C$

[16] Pogrebnjak A. D., Pshyk A. V., Beresnev V. M., Zhollybekov B. R.: Protection of specimens against friction and wear using titanium-based multicomponent nanocomposite coatings: A review. Journal of Friction and Wear, 35, 55-66 (2014)

DOI: $10.3103 / \mathrm{S} 1068366614010073$

[17] Sahasrabudhe H., Soderlind J., Bandyopadhyay A.: Laser processing of in situ TiN/Ti composite coating on titanium. Journal of the Mechanical Behavior of Biomedical Materials, 53, 239-249 (2016).

DOI: $10.1016 /$ j.jmbbm.2015.08.013

[18] Slepička P., Neděla O., Siegel J., Krajcar R., Kolská Z., Švorčik V.: Ripple polystyrene nano-pattern induced by KrF laser. Express Polymer Letters, 8, 459-466 (2014). DOI: $10.3144 /$ expresspolymlett.2014.50

[19] Slepička P., Michaljaničová I., Švorčik V.: Controlled biopolymer roughness induced by plasma and excimer laser treatment. Express Polymer Letters, 7, 950-958 (2013).

DOI: $10.3144 /$ expresspolymlett.2013.92

[20] Sridharan K., Anders S., Nastasi M., Walter K. C., Anders A., Monteiro O. R., Ensinger W.: Nonsemiconductor applications of PIII\&D. in 'Handbook of plasma immersion ion implantation and deposition' (ed.: Anders A.) Wiley-VCH, Weinheim, 553-636 (2004).

[21] Fink D.: Fundamental sof ion-irradiated polymers. Springer, Berlin (2004).

[22] Kondyurin, A., Bilek M.: Ion beamtreatment of polymers, application aspects from medicine to space. Elsevier, Amsterdam (2008).

[23] Tóth A., Kereszturi K., Mohai M., Bertóti I.: Plasma based ion implantation of engineering polymers. Surface and Coatings Technology, 204, 2898-2908 (2010). DOI: $10.1016 /$ j.surfcoat.2009.12.004

[24] Kereszturi K., Tóth A., Mohai M., Bertóti I.: Surface chemical and nanomechanical alterations in plasma immersion ion implanted PET. Surface and Interface Analysis, 40, 664-667 (2008). DOI: $10.1002 /$ sia.2643 
[25] Kereszturi K., Tóth A., Mohai M., Bertóti I., Szépvölgyi J.: Nitrogen plasma-based ion implantation of poly (tetrafluoroethylene): Effect of the main parameters on the surface properties. Applied Surface Science, 256, 6385-6389 (2010).

DOI: $10.1016 /$ j.apsusc.2010.04.021

[26] Kalácska G., Zsidai L., Keresztes R., Tóth A., Mohai M., Szépvölgyi J.: Effect of nitrogen plasma immersion ion implantation of polyamide- 6 on its sliding properties against steel surface. Wear, 290-291, 66-73 (2012). DOI: $10.1016 /$ j.wear.2012.05.011

[27] Kalácska G., Zsidai L., Kereszturi K., Mohai M., Tóth A.: Sliding tribological properties of untreated and PIIItreated PETP. Applied Surface Science, 255, 58475850 (2009).

DOI: $10.1016 /$ j.apsusc. 2009.01.017

[28] Tóth A., Bertóti I., Mohai M., Ujvári T.: Surface modification of polyethylene by nitrogen PIII: Surface chemical and nanomechanical properties. Materials Science Forum, 537-538, 255-262 (2007).

DOI: 10.4028/www.scientific.net/MSF.537-538.255

[29] Bertóti I., Mohai M., Tóth A., Ujvári T.: Nitrogen-PBII modification of ultra-high molecular weight polyethylene: Composition, structure and nanomechanical properties. Surface and Coatings Technology, 201, 68396842 (2007).

DOI: $10.1016 /$ j.surfcoat.2006.09.022
[30] Zsidai L., Samyn P., Vercammen K., Van Acker K., Kozma M., Kalácska G., De Baets P.: Friction and thermal effects of engineering plastics sliding against steel and DLN-coated counterfaces. Tribology Letters, 17, 269-288 (2004).

DOI: 10.1023/B:TRIL.0000032453.09366.d4

[31] Tóth A., Bertóti I., Szilágyi E., Dong H., Bell T., Juhász A., Nagy P. M.: Surface characterization of ultrahigh molecular weight polyethylene after nitrogen ion implantation. Surface and Interface Analysis, 30, 434438 (2000).

DOI: 10.1002/1096-9918(200008)30:1<434::AIDSIA 788 $>3.0 . \mathrm{CO} ; 2-\mathrm{W}$

[32] Fraidenraich N., Vilela O. C.: Exact solutions for multilayer optical structures.: Application to PV modules. Solar Energy, 69, 357-362 (2000). DOI: $10.1016 / \mathrm{S} 0038-092 \mathrm{X}(00) 00109-2$

[33] Haber I. E., Farkas I.: Combining CFD simulations with blockoriented heatflow-network model for prediction of photovoltaic energy-production. Journal of Physics: Conference Series, 268, 012008/1-012008/7 (2011). DOI: $10.1088 / 1742-6596 / 268 / 1 / 012008$

[34] Iserrmann R.: Mechatronic systems fundamentals. Springer-Verlag, London (2005). 